Research Paper

Received: 12 December 2012 / Revised: 26 February 2013 / Accepted: 4 March 2013

\title{
Electrochemical investigation of the interaction between lysozyme-shelled microbubbles and vitamin $\mathrm{C}$
}

\author{
Francesca Cavalieri $^{1,2}$, Laura Micheli ${ }^{1,3, 凶}$, Meifang Zhou $^{2}$, Mariarosaria Tortora ${ }^{1}$, Giuseppe Palleschi ${ }^{1,3}$, Muthupandian \\ Ashokkumar ${ }^{2, 凶}$ \\ ${ }^{1}$ Dipartimento di Scienze e Tecnologie Chimiche, Università di Roma “Tor Vergata”, Via della Ricerca Scientifica, \\ 00173 Roma, Italia \\ ${ }^{2}$ School of Chemistry, The University of Melbourne, Melbourne, Victoria 3010, Australia \\ ${ }^{3}$ Consorzio Interuniversitario Biostrutture e Biosistemi "INBB", Viale Medaglie d' Oro 305, 00136 Rome, Italy \\ $\square$ Corresponding authors: \\ Dr L. Micheli \\ Phone: $+390672594420 ;$ Fax +390672594328 \\ E-mail: micheliniroma2.it \\ Professor M. Ashokkumar \\ Phone: +61383447090. Fax: +61-3-93475180. \\ E-mail: masho@unimelb.edu.au.
}

\begin{abstract}
We report loading of vitamin C (ascorbic acid) on to lysozyme-shelled microbubbles. The interaction between lysozyme-shelled microbubbles and vitamin $\mathrm{C}$ was studied by use of cyclic and differential pulse voltammetry, zeta potential measurements, and scanning electron microscopy. The effect of microbubbles on electrochemical measurement of ascorbic acid was evaluated. The linear range for ascorbic acid obtained for differential pulse measurement in the presence of $1 \mathrm{mg} \mathrm{mL}^{-1}$ microbubbles was $1-50 \mu \mathrm{mol} \mathrm{L}^{-1}\left(y=0.067 x+0.130, r^{2}=0.995\right)$, with a detection limit of $0.5 \mu \mathrm{mol} \mathrm{L}{ }^{-1}$. The experimental conditions, i.e., $\mathrm{pH}$ and ionic strength, were optimized to improve the interaction between ascorbic acid and lysozyme-shelled microbubbles. The results were satisfactory when the interaction was performed for $1 \mathrm{~h}$ in aqueous solution at $\mathrm{pH}$. The amount of vitamin $\mathrm{C}$ loaded on the microbubbles ( $90 \%$ of the analyte added, $R S D_{\text {inter-expt. }}=3 \%, n=6$ ) and the stability of microbubbles-ascorbic acid complex (until $72 \mathrm{~h}$ at $25^{\circ} \mathrm{C}$ ) were also evaluated by use of differential pulse voltammetry and zeta potential measurements.
\end{abstract}

\section{Keywords}

Lysozyme microbubbles - ascorbic acid - electrostatic interaction - electrochemical technique

\section{Introduction}

The purpose of targeted drug delivery is to improve the therapeutic efficacy of drugs in specific regions, for example tumor cells, with minimum side effects, for example toxicity to healthy tissue [1]. Microbubbles, $\mu \mathrm{Bs}$, are small (typically $0.5-8 \mu \mathrm{m}$ in diameter) gas-filled microspheres stabilized by a lipid, protein, or polymer shell [2,3]. $\mu \mathrm{Bs}$ are currently used as contrast agents in diagnostics. Their movement through the vasculature is unobstructed, and they increase backscattered acoustic signals in living tissue $[4,5]$. In addition to diagnostic applications, $\mu \mathrm{Bs}$ are promising sonoresponsive drug carriers. $\mu \mathrm{Bs}$ can be disrupted by use of a localized ultrasonic pulse to release therapeutic agents at targeted sites [6]. We recently reported a flow-through sonication technique for synthesizing stable and monodisperse lysozyme shelled micro and/or nanobubbles, LS $\mu$ Bs, with potential applications in diagnostics and gene therapy [7-10]. Proteins and nucleic acids [7, 9] can be conjugated to the LS $\mu$ Bs shell [10], exploiting the hydrophobic and/or electrostatic and/or covalent interactions with the amino carboxyl, and thiol functional groups of lysozyme. Because the isoelectric point of lysozyme is 10 , LS $\mu \mathrm{Bs}$ are positively charged colloidal particles ( $\zeta$ potential $+40 \pm 3 \mathrm{mV})$ at $\mathrm{pH} 7$. The positively charged surface of LS $\mu \mathrm{Bs}$ is a good template for assembly of negatively charged molecules. Ascorbic acid, known as vitamin $\mathrm{C}$, has a variety of biological, pharmaceutical, and dermatological functions [11]. It is a potent antioxidant capable of reversing endothelial dysfunction caused by increased oxidant stress. It also promotes 
collagen biosynthesis, provides photoprotection, causes melanin reduction, scavenges free radicals, and enhances immunity $[12,13]$. In animal models of sepsis, intravenous ascorbate injection increases survival and protects several microvascular functions, including capillary blood flow, the microvascular permeability barrier, and arteriolar responsiveness to vasoconstrictors and vasodilators. Ascorbate accumulates in microvascular endothelial cells, scavenges reactive oxygen species, and stimulates nitric oxide production by endothelial nitric oxide synthase [14]. Analysis of ascorbic acid in solution is usually based on its electrochemical and colorimetric properties. Several analytical methods using voltammetric, amperometric, and spectrophotometric techniques [15-19] have been reported. Electrochemical techniques have been used for the determination of ascorbic acid with the advantage of no need for derivatisation. Cyclic voltammetry (CV) of ascorbic acid furnishes an irreversible anodic peak at approximately 450$500 \mathrm{mV}[20]$.

Herein, we report loading of vitamin C (ascorbic acid) on to LS $\mu$ Bs and characterization of the electrochemical properties of the ascorbic acid-LS $\mu$ B complex, hereafter referred to as AA-LS $\mu$ B. Ascorbic acid is an electroactive compound bearing a negative charge in a specific solution $\mathrm{pH}$ range delocalized between the two oxygen atoms present in the structure (Fig. 1b). Electrostatic interaction between the positively charged surface of LS $\mu$ Bs and ascorbic acid was exploited to load the electroactive agent on to the $\mu \mathrm{B}$ shell.

Interaction of ascorbic acid with LS $\mu$ Bs and the colloidal stability of the resulting complex were studied. The experimental conditions were optimized to improve the efficiency of the interaction between ascorbic acid and LS $\mu B s$. $\zeta$ potential measurements were also used to optimize the loading conditions without compromising the colloidal stability of $\mu \mathrm{Bs}$. The redox properties of ascorbic acid immobilized on to LS $\mu$ Bs were studied by use of differential pulse voltammetry (DPV).

The proposed method of loading vitamin $\mathrm{C}$ has the potential to enable intravenous administration of ascorbic acid combined with an ultrasound contrast agent for local release of high concentrations of vitamin $\mathrm{C}$ by use of an acoustic stimulus, as shown in Fig. 1a.

\section{Experimental}

\section{Reagents and solutions}

All reagents were of the highest available grade. Hen egg white lysozyme and DL-dithiothreitol (DTT) were purchased from Fluka (Castle Hill, Australia). L-Ascorbic acid, potassium chloride, and sodium chloride were purchased from Sigma-Aldrich (Castle Hill, Australia). All buffer solutions were prepared with Milli-Q water obtained from a Millipore RiOs/Origin system (18.2 $\mathrm{M} \Omega \mathrm{cm}^{-1}$ at $\left.25^{\circ} \mathrm{C}\right)$.

\section{Preparation of LSHBs}

Lysozyme $(5 \% w / v)$ solution was prepared in $5 \mathrm{~mL}$ Tris buffer $\left(0.1 \mathrm{~mol} \mathrm{~L}^{-1}\right)$ at $\mathrm{pH}$ 8.0. Lysozyme was denatured by adding DTT $(0.15 \mathrm{~g})$ and stirring for $2 \mathrm{~min}$. A Brason $20-\mathrm{kHz}$ ultrasound generator with a standard 3 mm diameter horn and adjustable power intensity was used for emulsification and cross-linking of protein molecules in aqueous media [7, 10]. The tip of the high-intensity ultrasonic horn was positioned at the protein solution-air interface. After ultrasonic irradiation at an applied acoustic power of $160 \mathrm{~W}$ for $30 \mathrm{~s}$, the LS $\mu \mathrm{B}$ suspension was washed five times with MilliQ water to remove DTT and residual protein. The floating LS $\mu$ Bs were collected after each washing.

\section{BCA procedure}

The amount of lysozyme in LS $\mu$ Bs was determined by biochemical colorimetric assay (Bicinchoninic Acid Kit for Protein determination; Sigma, Castle Hill, Australia). The amount of the protein present was quantified by measurement of absorption at $562 \mathrm{~nm}$. The results were compared with those obtained gravimetrically [21-23]. For gravimetric calculation of the concentration of $\mathrm{LS} \mu \mathrm{Bs}$ the microbubbles suspension was washed several times with Milli-Q water by flotation, to remove any unreacted lysozyme, and $1 \mathrm{~mL}$ of LS $\mu \mathrm{B}$ aqueous suspension was dried and weighed.

\section{Determination of free sulfhydryl groups}

The amount of free-SH groups present on the surface of the microbubbles was determined by Ellman's method [25]. Mixtures of $1 \mathrm{~mL}$ of microbubbles solution $\left(1 \mathrm{mg} \mathrm{mL}^{-1}\right)$ and $2.0 \mathrm{~mL}$ Tris buffer $(10.4 \mathrm{~g}$ Tris (trihydroxymethyl aminomethane), $6.9 \mathrm{~g}$ glycine, and $1.2 \mathrm{~g}$ EDTA in $1 \mathrm{~L}$ deionized water at $\mathrm{pH}$ 8.0) and $0.02 \mathrm{~mL}$ Ellman's reagent (0.2 $\mathrm{g}$ DTNB (5,5'-dithio-2-nitrobenzoate) in $50 \mathrm{~mL}$ Tris buffer), were mixed and reacted at $25^{\circ} \mathrm{C}$ for 5 min. The absorbance 
was then measured at $412 \mathrm{~nm}$, with reacted solutions with no microbubbles as blank and microbubbles with no Ellman's reagent for determination of the turbidity.

\section{Preparation of ascorbic acid-microbubbles complex (AA-LS $\mu$ Bs)}

Different amounts of ascorbic acid were added to a fixed amount of LS $\mu$ Bs ( $1 \mathrm{mg} \mathrm{mL}^{-1}$, determined by BCA assay) and incubated for $1 \mathrm{~h}$ with mild stirring at room temperature. The LS $\mu \mathrm{B}-\mathrm{AA}$ complex was then washed three times with MilliQ water to remove the unreacted ascorbic acid. The complex was stored at $25{ }^{\circ} \mathrm{C}$ in MilliQ water in the dark and was stable for three days.

To optimize the yield of the AA-LS $\mu \mathrm{B}$ complex, different experimental conditions were used. The $\mathrm{NaCl}$ concentration $\left(0,0.01,0.05,0.1,0.5 \mathrm{~mol} \mathrm{~L}^{-1}\right)$ and $\mathrm{pH}(4,6,8)$ of the incubation solution were varied. The ascorbic acid loading efficiency was evaluated by measuring the concentration of AA used for the incubation, the amount of ascorbic acid loaded on to the microbubbles, and the amount of ascorbic acid present in the washing solution. This enabled determination of whether ascorbic acid was converted into an inactive form under the reaction conditions [24].

\section{Apparatus and measurements}

The interaction between ascorbic acid and LS $\mu$ Bs was monitored by use of zeta potential measurements (ZetaPals Phase Analysis Light Scattering, model BI-Zel AQ-92 electrode assembly and BI-SCP). With this technique the capacity of LS $\mu$ Bs to interact with ascorbic acid and the stability of the complex formed, AA-LS $\mu$ B, were studied and correlated with $\mathrm{pH}$ (between 3 and 8 ) and ionic strength $\left(\mathrm{NaCl}\right.$ concentration between $\left.0.01-0.5 \mathrm{~mol} \mathrm{~L}^{-1}\right)$ of the solutions. All measurements were performed at room temperature in aqueous solutions.

Electrochemical measurements were performed with a MacLab/2e (AD Instruments, Australia). Voltammetric measurements were performed with a screen-printed electrode produced in house; it consisted of a three electrode configuration with graphite working and counter electrodes and a silver pseudo-reference electrode printed on a plastic support film. The $\mathrm{CV}$ conditions were: start potential $-0.25 \mathrm{~V}$, first vertex potential $1.00 \mathrm{~V}$, second vertex potential $-0.25 \mathrm{~V}$, step potential $2 \mathrm{~ms}$, scan rate $50 \mathrm{mV} \mathrm{s}^{-1}$. The differential pulse voltammetry (DPV) conditions were: pulse amplitude $60 \mathrm{mV}$, pulse width $100 \mathrm{~ms}$, scan rate $50 \mathrm{mV} \mathrm{s}^{-1}$. All measurements were performed in $0.1 \mathrm{~mol} \mathrm{~L}^{-1} \mathrm{KCl}$ aqueous solutions at room temperature. Cyclic voltammetry measurements (CV) were performed with $60 \mu \mathrm{L} L S \mu B s$, ascorbic acid, and lysozyme solutions to observe the electrochemical behavior of each analyte. The same study was performed by use of DPV. To understand how the presence of the protein (lysozyme or LS $\mu$ Bs) could interfere with the electrochemical response to ascorbic acid, DPV measurements were performed using $60 \mu \mathrm{L}$ lysozyme-ascorbic acid or $\mu \mathrm{B}$-ascorbic acid mixture.

A DPV calibration curve for ascorbic acid was obtained by use of increasing amounts $\left(0-5 \times 10^{-3} \mathrm{~mol} \mathrm{~L}^{-1}\right)$ of the analyte (standard solutions) in $0.1 \mathrm{~mol} \mathrm{~L}{ }^{-1} \mathrm{KCl}$. The amount of ascorbic acid absorbed on the surface of $\mu \mathrm{Bs}$ was determined by use of this calibration curve. The measurements were repeated three times and the relative standard deviation $(R S D, \%)$ was calculated.

Spectrophotometric measurements were performed with a Cary 50 UV-visible spectrophotometer. The morphology of LS $\mu$ Bs and the AA-LS $\mu$ B complex was studied by scanning electron microscopy (SEM) and use of an inverted Olympus IX71 wide-field microscope with a 60× objective lens and a CCD camera (Cool SNAP fx; Photometrics, Tucson, AZ, USA).

\section{Results and discussion}

The mechanism of ultrasonic generation of LS $\mu$ Bs has been described elsewhere [7, 10]. In brief, lysozyme was denatured by adding DTT. Emulsification of air bubbles induced by a $20-\mathrm{kHz}$ ultrasound horn in an aqueous protein solution creates a suspension of $\mu \mathrm{Bs}$. Aggregation of denatured lysozyme at the bubble-solution interface contributes to stabilization of $\mu \mathrm{Bs}$. The protein shell was further stabilized by inter-protein disulfide cross-linking of cysteine residues induced by the superoxide radicals generated during cavitation. The diameter and shell thickness of lysozyme were $2.5 \pm 0.5 \mu \mathrm{m}$ and $150 \pm 50 \mathrm{~nm}$, respectively [10]. Unreacted free thiols remaining on the shell preserve a reducing environment in the $\mu \mathrm{Bs}$. The concentration of LS $\mu$ Bs was determined by use of a gravimetric method and by BCA assay. The concentration of free unreacted thiols present on the surface of the microbubbles was determined by Ellman's method [25]. Table 1 shows the concentration of the $\mu \mathrm{B}$ suspension and the concentration of thiols. The measurements were performed in triplicate on three independent preparations of LS $\mu$ Bs.

\section{Optimization of electrochemical studies}


The electrochemical behavior of aqueous solutions containing lysozyme $\left(1 \mathrm{mg} \mathrm{mL}^{-1}\right), \mathrm{LS} \mu \mathrm{Bs}\left(1 \mathrm{mg} \mathrm{mL}{ }^{-1}\right)$, ascorbic acid $\left(10 \mathrm{mg} \mathrm{mL}^{-1}\right)$, and the $\mathrm{LS} \mu \mathrm{B}-\mathrm{AA}$ mixture was determined by use of $\mathrm{CV}$ measurements to understand the electrochemical response of each analyte separately and in the mixture. The results obtained for each analyte are shown in Fig. 2. Ascorbic acid furnished an anodic oxidation peak at approximately $450-500 \mathrm{mV}$; the voltammograms obtained from LS $\mu$ Bs and lysozyme solution did not contain this peak but a low-intensity signal was observed at high potential [26]. These results were confirmed by DPV analysis, a technique much more sensitive than CV. The DPV voltammograms acquired for lysozyme, ascorbic acid, and a mixture of ascorbic acid and lysozyme are shown in Fig. 3a, and the DPV voltammograms acquired for LS $\mu$ Bs, ascorbic acid, and the mixture of ascorbic acid and LS $\mu$ Bs are compared in Fig. 3b. These results suggest that both the lysozyme solution and the LS $\mu$ B suspension are electrochemically oxidized in the range $800-900 \mathrm{mV}$, as expected. In fact, voltammetric studies of lysozyme have revealed the oxidation current of tyrosine and tryptophan residues of the protein with adsorption of the lysozyme on the graphite electrode surface [26, 27].

It must be noted that the protein does not affect the electrochemical response of ascorbic acid, although a shift in the ascorbic acid oxidation potential because of ascorbic acid-protein interaction was observed. This behavior has been observed for other electroactive analytes when interacting with proteins [28]. However we observed a reduction of the value of the current for the AA-protein mixture at the same ascorbic acid concentration, probably because of the presence of the protein (LS $\mu$ Bs or lysozyme). Lysozyme may be adsorbed by the electrode surface, thereby precluding AA from easily accessing the electrode [27, 29]. The different currents observed for ascorbic acid in the presence of lysozyme and LS $\mu \mathrm{Bs}$ were ascribed to the different concentrations of proteins present and to their different state of aggregation. A comparable result was also obtained for the complex AA-LS $\mu$ B, for which loading of ascorbic acid on to microbubbles was performed in MilliQ water for $60 \mathrm{~min}$ (data not shown). In this case the peak is slightly shifted because of its interaction with the surface of the LS $\mu$ Bs. These results indicate that these electrochemical techniques can be used to determine the electrochemical response of immobilized ascorbic acid on the surface of the LS $\mu$ Bs and to quantify the amount of ascorbic acid loaded on the LS $\mu$ B shell as a result of the electrostatic interaction.

DPV was performed to evaluate the amount of ascorbic acid in the presence of LS $\mu$ Bs. In Fig. 4a the acquired peaks indicate the sensitivity of the measurement and the absence of the interference by the $\mu$ Bs present. A calibration curve (Fig. 4b) was constructed by using different concentrations $\left(0-50 \mu \mathrm{mol} \mathrm{L}{ }^{-1}\right)$ of ascorbic acid while keeping the $\mu \mathrm{B}$ concentration fixed $\left(1 \mathrm{mg} \mathrm{mL}{ }^{-1}\right)$. The results showed the working range was between 1 and $50 \mu \mathrm{mol} \mathrm{L} \mathrm{L}^{-1}$ $\left(y=0.067 x+0.130, r^{2}=0.995\right)$, with a detection limit of $0.5 \mu \mathrm{mol} \mathrm{L} \mathrm{L}^{-1}$.

To improve the electrostatic interaction between ascorbic acid and the $\mu \mathrm{Bs}$ without compromising the colloidal stability of the $\mu \mathrm{Bs}$, the experimental conditions, for example ionic strength, $\mathrm{pH}$, incubation time, and the amount of ascorbic acid, were optimized. Ascorbic acid is a dibasic acid $\left(\mathrm{p} K_{\mathrm{a} 1}=4.04\right.$ and $\left.\mathrm{p} K_{\mathrm{a} 2}=11.3\right)$ [30]. The effect of $\mathrm{pH}$ on the efficiency of loading of ascorbic acid on to the microbubbles was investigated by loading at $\mathrm{pH} 4$, corresponding to $\mathrm{p} K_{\mathrm{a} 1}, \mathrm{pH} 6$ and $\mathrm{pH}$ 8. This study confirmed the poor stability of the $\mu \mathrm{Bs}$ at alkaline $(\geq 8)$ and acidic $(\leq 4) \mathrm{pH}$, with formation of an aggregate or pellet after $1 \mathrm{~h}$. The acidic denaturation and degradation of the protein could explain the poor stability of microbubbles at $\mathrm{pH} \leq 4$. The gas core is stabilized by a thick lysozyme shell. Hence degradation of the shell causes leakage of the gas. To optimize uptake of ascorbic acid by the shell of the LS $\mu$ Bs, the effect of ionic strength on LS $\mu \mathrm{B}$ loading capacity was also investigated, by incubating $\mathrm{LS} \mu \mathrm{Bs}$ with ascorbic acid dissolved in solutions containing different concentration of $\mathrm{NaCl}\left(0.01,0.05,0.1\right.$, and $\left.0.5 \mathrm{~mol} \mathrm{~L}^{-1}\right)$ at $\mathrm{pH} 6$ [31].

The AA-LS $\mu$ B complex was characterized by use of DPV and $\zeta$ potential measurements. The electrochemical results obtained for different ascorbic acid concentrations, $\mathrm{pH}$, and ionic strength are reported in Fig. 5. Figure 5a shows that incubation of $\mathrm{LS} \mu \mathrm{Bs}$ with increasing amounts of ascorbic acid from 0.1 to $10 \mathrm{mg} \mathrm{mL}^{-1}$ results in an increasing current response. Ascorbic acid concentrations higher than $10 \mathrm{mg} \mathrm{mL}^{-1}$ were found to be detrimental to the stability of $\mu \mathrm{Bs}$, inducing aggregation. These results suggest that the loading capacity of $\mu \mathrm{Bs}$ can be maximized by using an ascorbic acid concentration of $10 \mathrm{mg} \mathrm{mL}^{-1}$. Figures $5 \mathrm{~b}$ and $5 \mathrm{c}$ show the measured currents as functions of $\mathrm{pH}$ and ionic strength, respectively. Figure $5 \mathrm{~b}$ shows that maximum loading of ascorbic acid is achieved at $\mathrm{pH} 6$. Despite the good loading capacity of $\mathrm{LS} \mu \mathrm{Bs}$ at $\mathrm{pH} 4$, as already mentioned, we observed formation of aggregates of microbubbles. Because the isoelectric point of lysozyme is 10 , at $\mathrm{pH}>8$ the $\mathrm{LS} \mu \mathrm{Bs}$ lose the electrostatic stabilization derived from the highly charged surface and consequently aggregate. Incubation at $\mathrm{pH} 6$ was found to be best for maximizing the electrostatic interaction between ascorbic acid and the $\mu \mathrm{Bs}$. In addition, $\mathrm{pH} 6$ was ideal for stability of the microbubbles. At pH 8 the ascorbic acid is present as a dehydroascorbic acid salt, losing its electroactive properties in the oxidation region [1820].

Interestingly, at pH 6 (Fig. 5c) the measured current $(\sim 30 \mu \mathrm{A})$ and, consequently, the ascorbic acid loading capacity of the $\mu \mathrm{Bs}$, is independent of $\mathrm{NaCl}$ concentration. As a matter of fact, the screening effect exerted by salt ions on the surface charge of the $\mu \mathrm{Bs}$ causes a decrease in potential (Fig. 6a). However the salt shielding effect, shown in Fig. 5c, does not affect either the electrostatic binding efficiency of AA or the colloidal stability of LS $\mu$ Bs (Fig. 7a). Conversely $\mathrm{LS} \mu \mathrm{Bs}$ in the presence of a high concentration of salt, without ascorbic acid, tend to aggregate. These results indicate ascorbic acid displaces salt ions from the LS $\mu$ B surface and strongly interacts with the positively charged amino acids (lysine, hystidine) present on the surface of $\mu \mathrm{Bs}$.

As already mentioned, $\mu \mathrm{Bs}$ are positively charged colloidal particles with a $\zeta$ potential of $+48 \mathrm{mV}$. The $\zeta$ potential of $\mathrm{AA}-\mathrm{LS} \mu \mathrm{B}$, as a function of $\mathrm{pH}$, has a trend in agreement with the results obtained by use of DPV. At $\mathrm{pH} 8$ the high $\zeta$ potential, $48 \mathrm{mV}$, corresponds to a low peak current. The decrease of $\zeta$ potential to $22 \mathrm{mV}$ (Fig. $6 \mathrm{~b}$ ) on interaction with 
ascorbic acid indicates that analyte adsorption shields the LS $\mu \mathrm{B}$ surface charge. The low ascorbic acid loading measured at $\mathrm{pH} 8$ is ascribed to the partial activity of ascorbic acid in alkaline condition when it is spontaneously oxidized to a neutral non electroactive dehydroascorbate, which is not able to interact electrostatically with $\mu \mathrm{Bs}$. The measurements were repeated with different incubation times (10, 30, 60, and $120 \mathrm{~min})$ and assessment of the amount of immobilized ascorbic acid. The results obtained for 10 and $30 \mathrm{~min}$ did not reveal a significant amount of ascorbic acid on the $\mu \mathrm{Bs}$ (reduction of the LOD in DPV measurements). Only when the incubation time was increased to $60 \mathrm{~min}$ was the amount of ascorbic acid loaded satisfactory. The results obtained after an incubation for $120 \mathrm{~min}$ were similar to those obtained after 60 min, suggesting that LS $\mu$ Bs incubated with AA for 60 min were saturated and no longer able to interact with additional molecules of ascorbic acid. The best conditions, with the amounts of ascorbic acid measured in the washed solutions and on the $\mu \mathrm{Bs}$, are reported in Table 2. It is apparent that the amount of ascorbic acid loaded on the $\mu \mathrm{Bs}$ is $\sim 90 \%$ of the amount added. This result is confirmed by the amount of ascorbic acid detected in the solution $(\sim 10 \%)$. These analyses were repeated six times to check the reproducibility. The

electrochemical measurement demonstrated that the ascorbic acid present on microbubbles was stable for $72 \mathrm{~h}$ at $25^{\circ} \mathrm{C}$. Complexation of AA with LS $\mu$ Bs may prevent AA degradation and oxidation.

SEM images of LS $\mu$ Bs and of AA-LS $\mu$ B are shown in Fig. 7. The SEM images obtained for the LS $\mu$ Bs before (Fig. 7a) and after (Figs. 7b, c) interaction with ascorbic acid show that small white crystals were observed on the surface of the $\mu \mathrm{Bs}$, indicating the presence of this analyte. To determine the ability of LS $\mu$ Bs to release AA upon ultrasound irradiation, AA-LS $\mu$ Bs were treated by use of $1 \mathrm{MHz}$ ultrasound transducer. AA was only partially released (data not shown), and most of the AA remained electrostatically bound to the broken LS $\mu$ B shells.

\section{Conclusions}

It has been shown that lysozyme microbubbles can easily be complexed with ascorbic acid under specific experimental conditions. In this work we demonstrated that a molecule with a negative charge, for example ascorbic acid, is able to stably bind to the microbubbles by electrostatic interaction. It has been shown that electrochemical techniques can be used to determine the electrochemical response of immobilized ascorbic acid on the surface of the LS $\mu$ Bs and to quantify the amount of this analyte loaded on the $\mu \mathrm{B}$ shell as a result of the electrostatic interaction. Further studies are necessary to establish the stability of AA-LS $\mu \mathrm{B}$ complex in the freeze-dried state to improve its stability to enable use of such systems for drug delivery. In conclusion, we used AA as a typical electrochemically active therapeutic agent that can be efficiently carried by LS $\mu$ Bs. We showed that LS $\mu$ Bs do not affect the redox properties of AA. Because AA is active when embedded in LS $\mu$ Bs, release from the LS $\mu$ Bs may not be required. In addition, $\mathrm{LS} \mu \mathrm{Bs}$ provide sonoresponsive drug-delivery microdevices which can be imaged by use of a 10-MHz ultrasound scanner. Imaging of $\mathrm{LS} \mu \mathrm{Bs}$ enables monitoring of the location and accumulation of AA-LS $\mu \mathrm{B}$ in the body where AA exerts its antioxidant activity.

\section{Acknowledgments}

This work was funded by the Marie Curie IRSES $7^{\circ}$ FP European Project 2009-2010.

\section{References}

1. Misra R, Acharya S, Sahoo SK (2010) Drug Discov Today 15(19-20):842-50

2. Sirsi S, Borden M (2009) Bubble Sci Eng Technol 1(1-2):3-17

3. Cavalieri F, Zhou M, Tortora M, Baldassarri L, Ashokkumar M (2012) Curr Pharm Des 18(15):2135-51

4. Blomley MJ, Albrecht T, Cosgrove DO, Patel N, Jayaram V, Butler-Barnes J, Eckersley RJ, Bauer A, Schlief R (1999) Radiol 210:409-416

5. Hongjia Z, Rong X, Qiufang O, Lidian C, Baowei D, Ye H (2010) Eur J Rad 73(2):288-293

6. Pitt WG, Husseini GA, Staples BJ (2004) Expert Opin Drug Deliv 1:37-56

7. Zhou M, Cavalieri F, Caruso F, Ashokkumar M (2012) ACS Macro Lett 1(7):853-856

8. Cavalieri F, Zhou M, Caruso F, Ashokkumar M (2011) Chem Commun 47:4096-4098

9. Melino S., Zhou M., Tortora M., Paci M., Cavalieri F., Ashokkumar M. (2012) Amino Acids 43(2):885-896

10. Zhou M., Cavalieri F., Ashokkumar M. (2011) Soft Matter 7:623-30

11. Englard S., Seifter S. (1986) Annu Rev Nutr 6:365-406

12. Mak S, Egri Z, Tanna G, Coleman R, Newton GE (2002) Am J Physiol Heart Circ Physiol 282:H2414-H2421

13. J. M. May (1999) FASEB J 13:995-1006

14. Wilson JX. (2009) BioFactors 35(1):5-13

15. Matos RC, Augelli MA, Pedrotti JJ, Lago CL, Angnes L (1998) Electroanal 10:653-658

16. Wring SA, Hart JP, Brich BJ (1990) Anal Chim Acta 229:63-70 
17. Pandy NK (1982) Anal Chem 54:793-796

18. Erdurak-Kiliç CS, Uslu B, Dogan B, Ozgen U, Ozkan SA, Coskun M (2006) J Anal Chem 61:1113-1120

19. Tiwari KK (2010) J Chin Chem Soc 57:105-110

20. Wang Z, Liu J, Liang Q, Wang Y, Luo G (2002) Analyst 127:653-658

21. Bradford MM (1976) Anal Biochem 72:248-254

22. Sorensen K, Brodbech U (1986) J Immunol Meth 95:291-293

23. Addis T, Poo LJ, Lew W, Yuen DW (1936) J Biol Chem 115:111-116

24. Nomura H, Ishiro T, Morimoto S (1969) Chem Pharm Bull 17:387-393

25. Ou S, Kwok KC, Wang Y, Bao H (2004) Food Chem. 88:317-320

26. Richards PG, Cloes B, Heptinstall J, Walton DJ (1994) Enzyme Microb Technol 16:795-801

27. Brabec V, Schindlerovà I (1981) Electrochem Bioelectrochem Bioenerg 8:451-458

28. Humble AV, Gado GM, Codd GA (1997) Water Res 7:1679-1686

29. Grieshaber D, MacKenzie R, Vörös J, Reimhult E (2008) Sensors 8:1400-1458

30. Wilson RJ, Breezer AE, Mitchell JC (1995) Thermochim Acta 27:27-40

31. Lee E, Kim K, Choi M, Lee Y, Park J, Kim B (2010) Drug Deliv 17(8):573-580

Fig. 1 (a) Schematic diagram of the interaction between LS $\mu$ Bs (positively charged) and AA (negatively charged). Ultrasound ( $U S$ )-assisted breakage of the shell of the LS $\mu$ Bs causes release of the drug located on the surface of the LS $\mu$ Bs. (b) Delocalization of negative charge on the ascorbic acid molecule

Fig. 2 Cyclic voltammograms of lysozyme (blue line), microbubbles (LS $\mathrm{BB}$ ) (green line), the AA-LS $\mu \mathrm{B}$ complex (yellow line), ascorbic acid $(A A)$ (brown line) and $0.1 \mathrm{~mol} \mathrm{~L}^{-1} \mathrm{KCl}$ (violet line). Concentrations: lysozyme $1 \mathrm{mg} \mathrm{mL}^{-1}$, $\mu \mathrm{B} 1 \mathrm{mg} \mathrm{mL} \mathrm{m}^{-1}$, ascorbic acid $10 \mathrm{mg} \mathrm{mL}^{-1}$. The measurements were conducted with a scan rate of $50 \mathrm{mV} \mathrm{s}^{-1}$. All measurements were performed in drops $(60 \mu \mathrm{L})$ at room temperature

Fig. 3 Differential pulse voltammograms obtained from lysozyme, ascorbic acid, and a mixture of lysozyme and AA in $0.1 \mathrm{~mol} \mathrm{~L}^{-1} \mathrm{KCl}$. The pulse amplitude was $60 \mathrm{mV}$, the pulse width $100 \mathrm{~ms}$, and the scan rate $50 \mathrm{mV} \mathrm{s}^{-1}$. All measurements were performed in drops $(60 \mu \mathrm{L})$ at room temperature. Continuous line, $10^{-5} \mathrm{~mol} \mathrm{~L}^{-1} \mathrm{AA}^{-1} 0.1 \mathrm{~mol} \mathrm{~L}-1$ $\mathrm{KCl}$; dashed line, $0.4 \mathrm{mmol} \mathrm{L}{ }^{-1}$ lysozyme $+10^{-5} \mathrm{~mol} \mathrm{~L}^{-1} \mathrm{AA}$ in $0.1 \mathrm{~mol} \mathrm{~L}{ }^{-1} \mathrm{KCl}$; dotted line, $0.1 \mathrm{~mol} \mathrm{~L}^{-1} \mathrm{KCl}$; dotted dashed line, $0.4 \mathrm{mmol} \mathrm{L}^{-1}$ lysozyme in $0.1 \mathrm{~mol} \mathrm{~L}^{-1} \mathrm{KCl}$

Fig. 4 Calibration for measurement of ascorbic acid in the presence of LS $\mu$ Bs $\left(1 \mathrm{mg} \mathrm{mL}^{-1}\right)$ : (a) DPV voltammetric measurements for ascorbic acid $\left(0-50 \mu \mathrm{mol} \mathrm{L}^{-1}\right)$ in $0.1 \mathrm{~mol} \mathrm{~L}{ }^{-1} \mathrm{KCl}$; (b) calibration curve for ascorbic acid obtained from the DPV peaks

Fig. 5 Currents measured for AA-LS $\mu$ B as a function of the experimental conditions used for incubation: (a) concentration of AA, (b) $\mathrm{pH},(\mathbf{c})$ ionic strength

Fig. 6 Zeta potential measurement for AA-LS $\mu \mathrm{B}$ as a function of the experimental conditions used for incubation: (a) ionic strength, (b) $\mathrm{pH}$

Fig. 7 SEM images of the LS $\mu$ Bs before (a) and after (b) the loading of AA. (c) Higher magnification of (b) shows small white crystals on the surface of the LS $\mu \mathrm{Bs}$, indicating the presence of AA

Table 1 Concentration of the LS $\mu$ Bs and amount of free thiols present on the LS $\mu$ Bs

\begin{tabular}{|l|l|l|}
\hline \multicolumn{2}{|l|}{$\mathrm{LS} \mu \mathrm{Bs}$ concentration $\left(\mathrm{mg} \mathrm{mL}^{-1}\right)$} & \multirow{2}{*}{ Free $-\mathrm{SH}$ on $\mathrm{LS} \mu \mathrm{B}\left(\mathrm{mmol} \mathrm{g}^{-1}\right)$} \\
\cline { 1 - 2 } By gravimetric method $(1 \mathrm{~mL})$ & By BCA $(10 \mathrm{~mL})$ & \\
\hline $0.5 \pm 0.3$ & $0.6 \pm 0.2$ & $0.777 \pm 0.002$ \\
\hline
\end{tabular}


Table 2 Results obtained for the interaction between ascorbic acid and LS $\mu \mathrm{B}\left(1 \mathrm{mg} \mathrm{mL} \mathrm{m}^{-1}\right)$

\begin{tabular}{|c|c|c|c|c|c|c|}
\hline & $\begin{array}{l}\text { Incubation time } \\
1 \mathrm{~h}\end{array}$ & $\begin{array}{l}\text { Recovery } \\
(\%)^{\mathrm{a}}\end{array}$ & $\begin{array}{l}R S D_{\text {inter-expt. }} \\
(n=6)\end{array}$ & $\begin{array}{l}\text { Incubation time } \\
2 \mathrm{~h}\end{array}$ & $\begin{array}{l}\text { Recovery } \\
(\%)^{\mathrm{a}}\end{array}$ & $\begin{array}{l}R S D_{\text {inter-expt. }} \\
(n=6)\end{array}$ \\
\hline pH 6 & $5.0 \pm 0.2 \mathrm{mmol} \mathrm{L}^{-1}$ & 89 & 3 & $5.0 \pm 0.2 \mathrm{mmol} \mathrm{L}^{-1}$ & 89 & 7 \\
\hline $\begin{array}{l}\mathrm{NaCl} \\
0.5 \mathrm{~mol} \mathrm{~L}^{-1}, \mathrm{pH} \\
6\end{array}$ & $4.9 \pm 0.1 \mathrm{mmol} \mathrm{L}^{-1}$ & 86 & 3 & $5 \pm 1 \mathrm{mmol} \mathrm{L}^{-1}$ & 87 & 22 \\
\hline $\mathrm{H}_{2} \mathrm{O}$ dist & $5 \pm 2 \mathrm{mmol} \mathrm{L}^{-1}$ & 87 & 19 & $5 \pm 4 \mathrm{mmol} \mathrm{L}^{-1}$ & 87 & 9 \\
\hline
\end{tabular}

\section{a mana}


a)

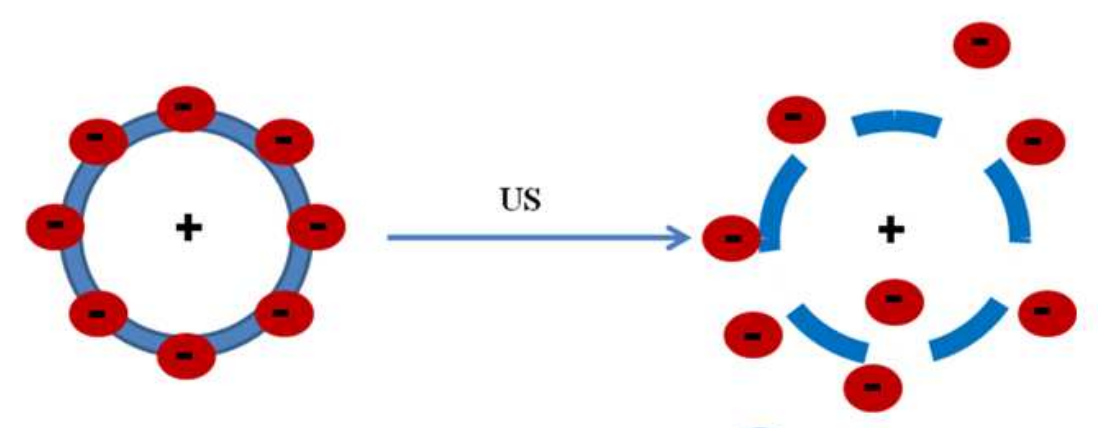

- Vitamin $\mathrm{C}$ or Ascorbic Acid $\quad$ Microbubbles

b)

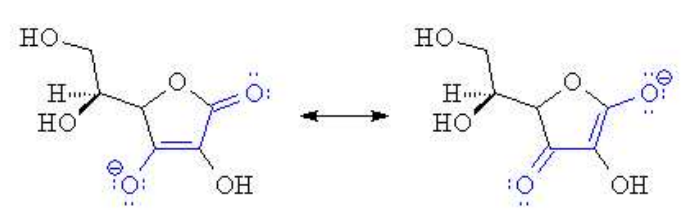




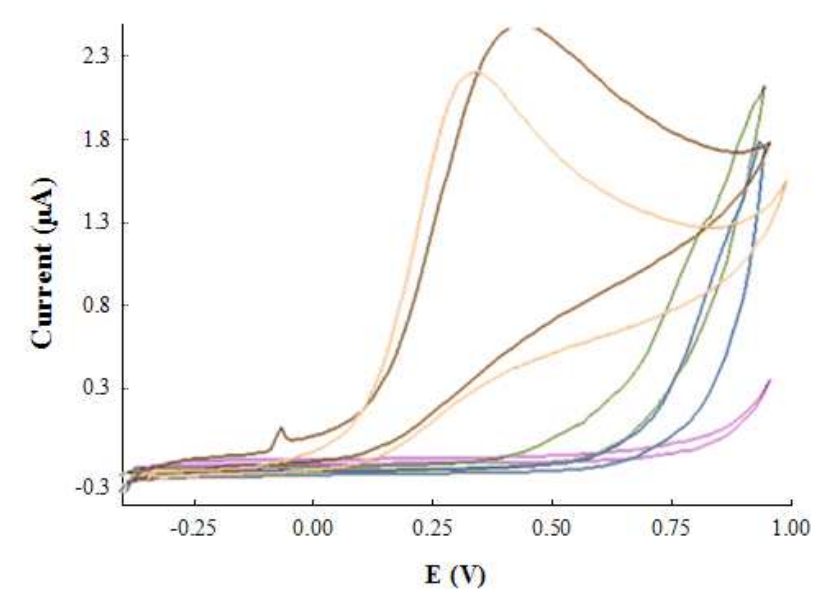

Figure 2 

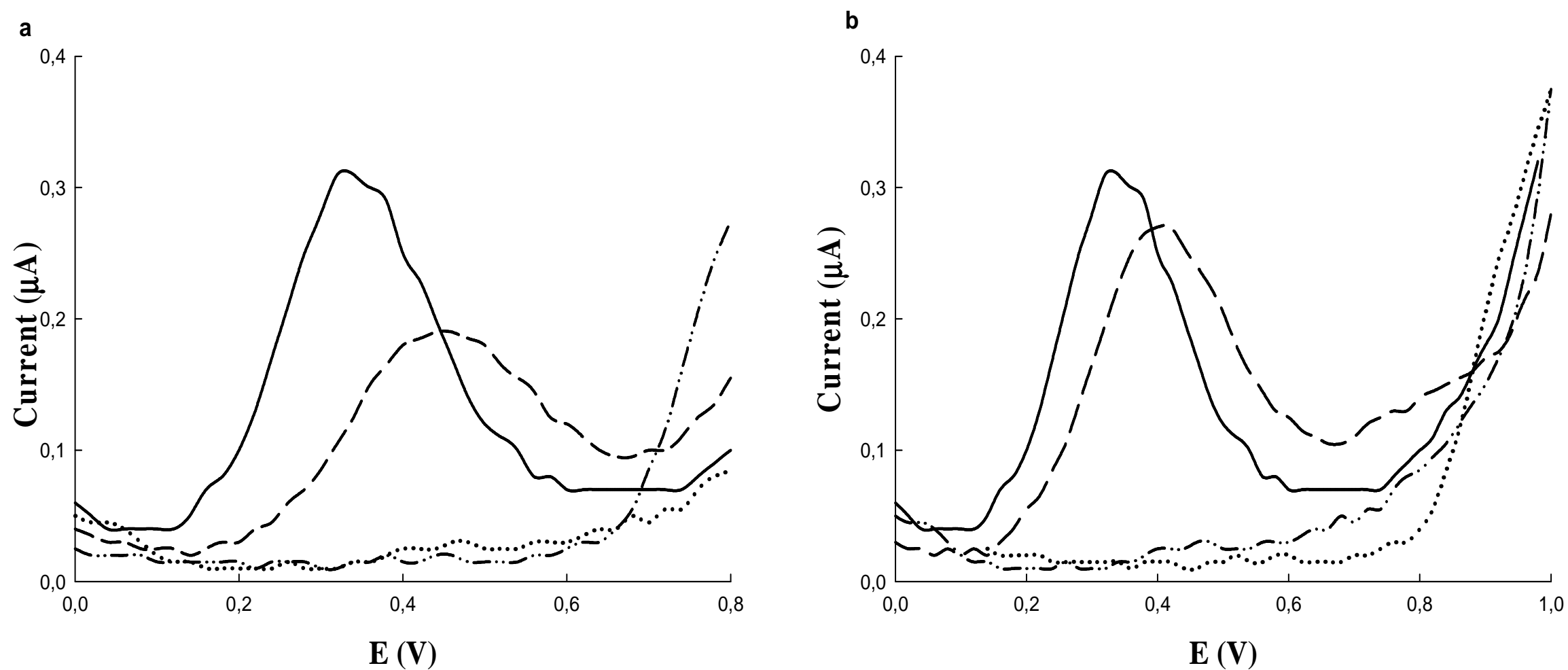

Figure 3 


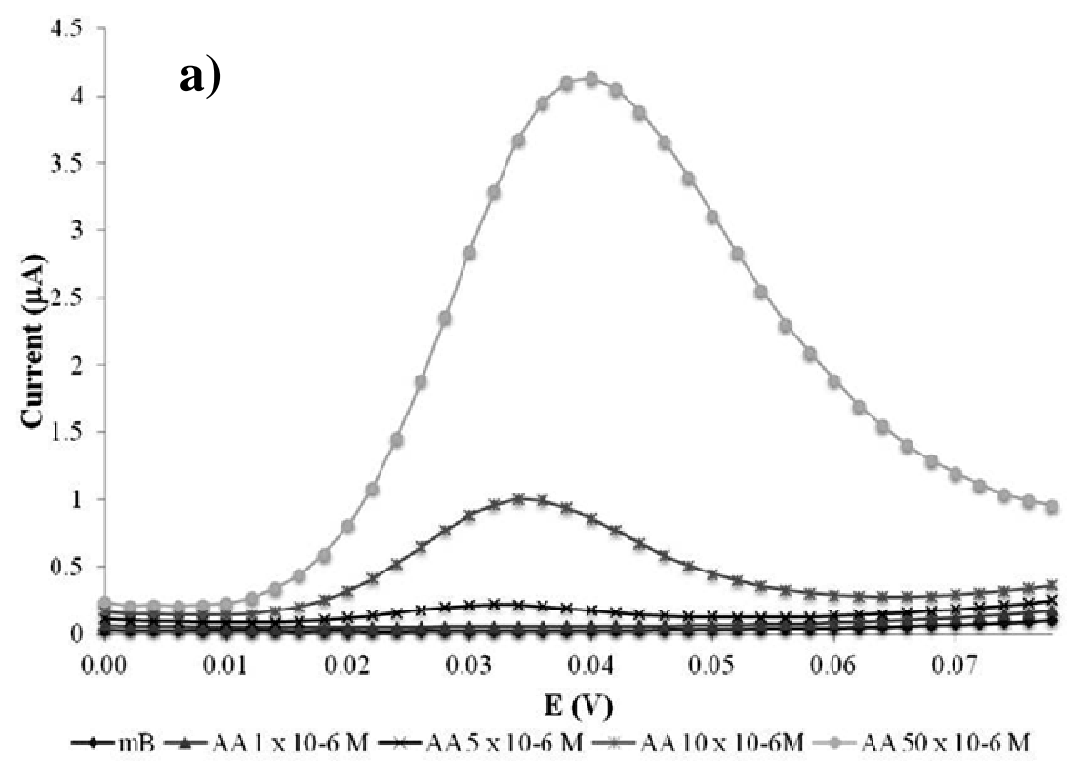

Figure 4

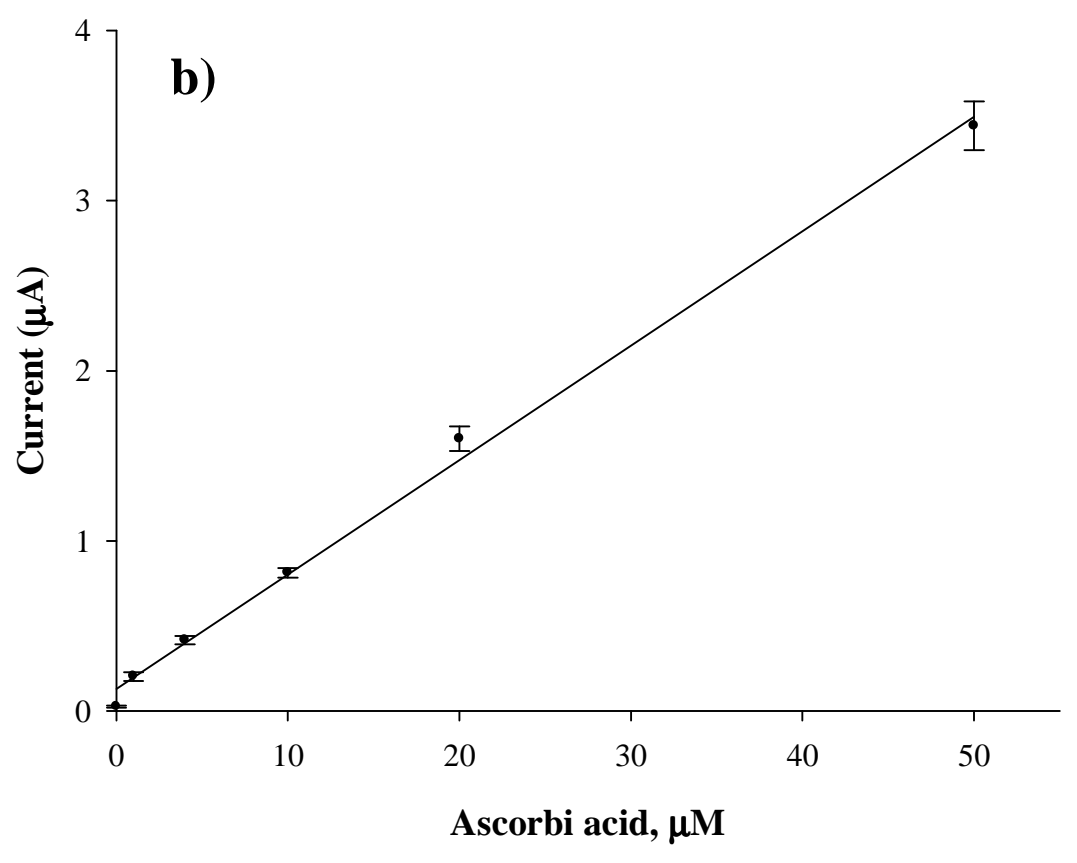



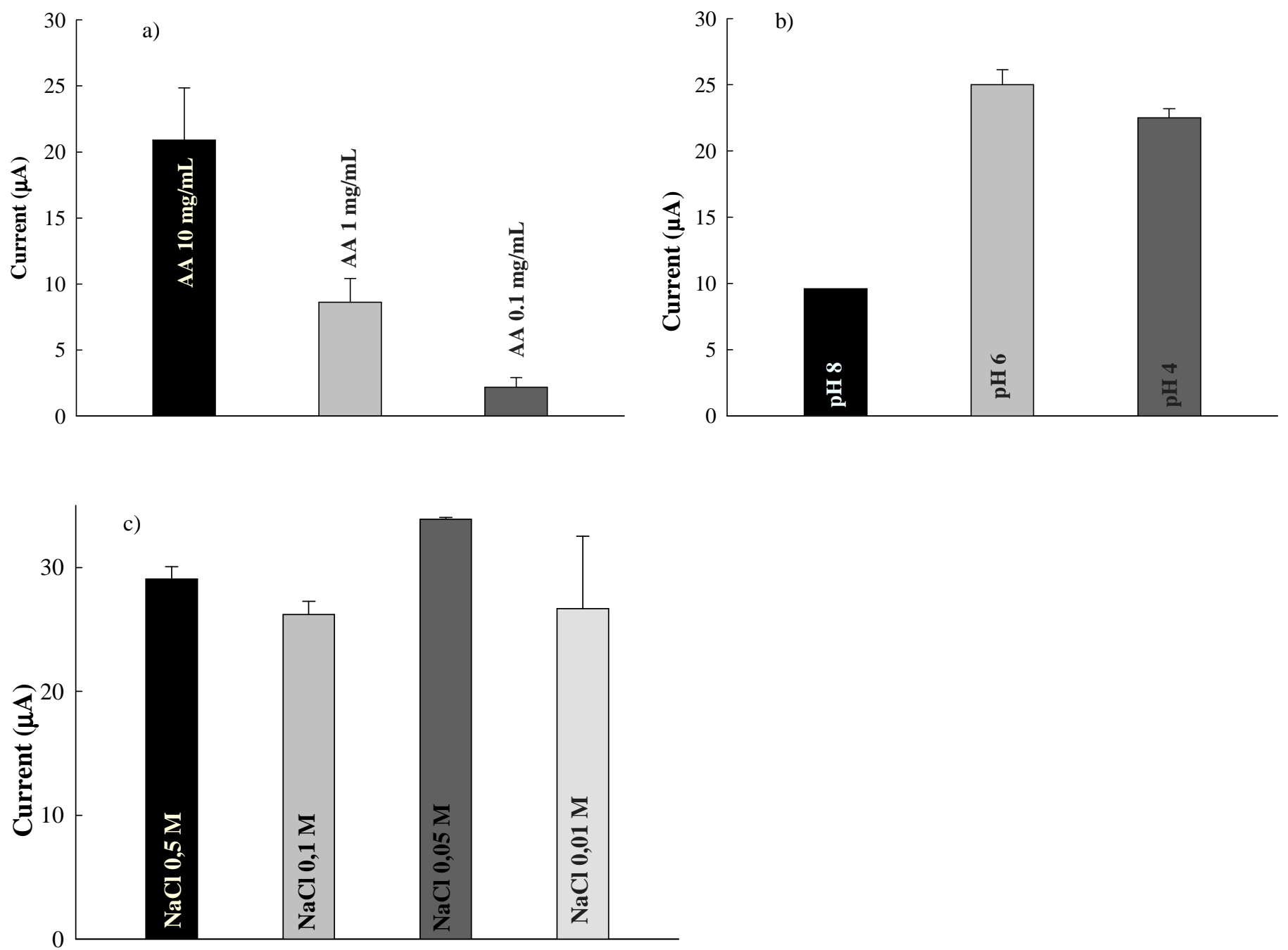

Figure 5. 
a)

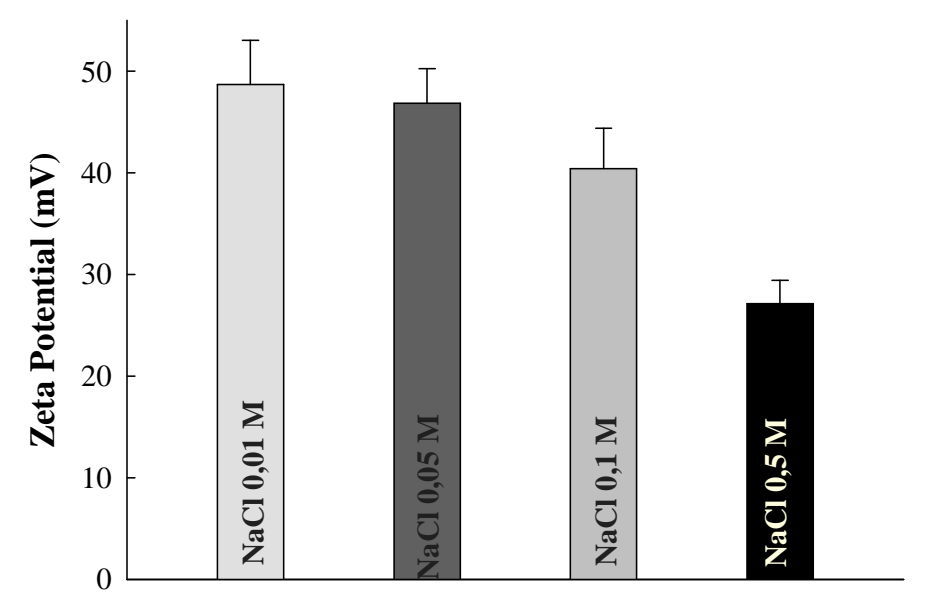

b)

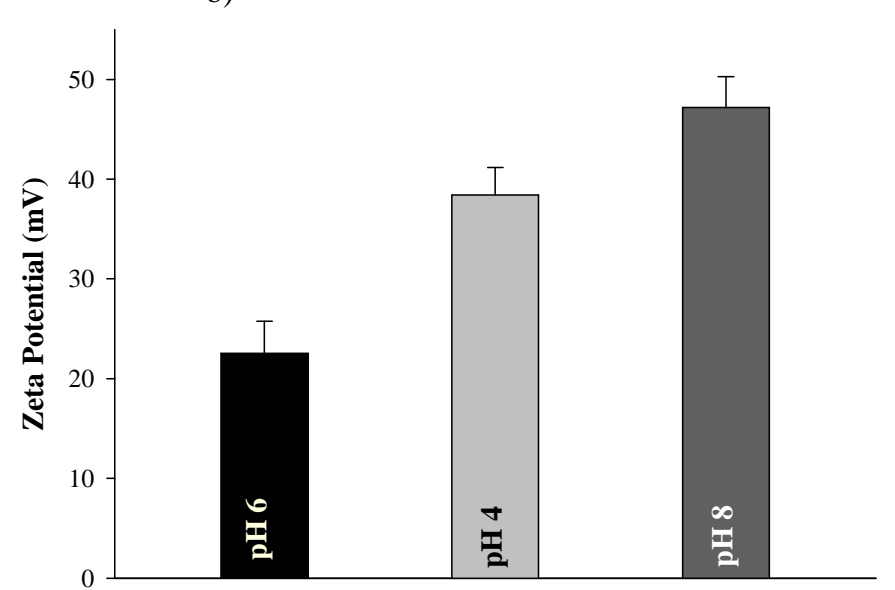

Figure 6 

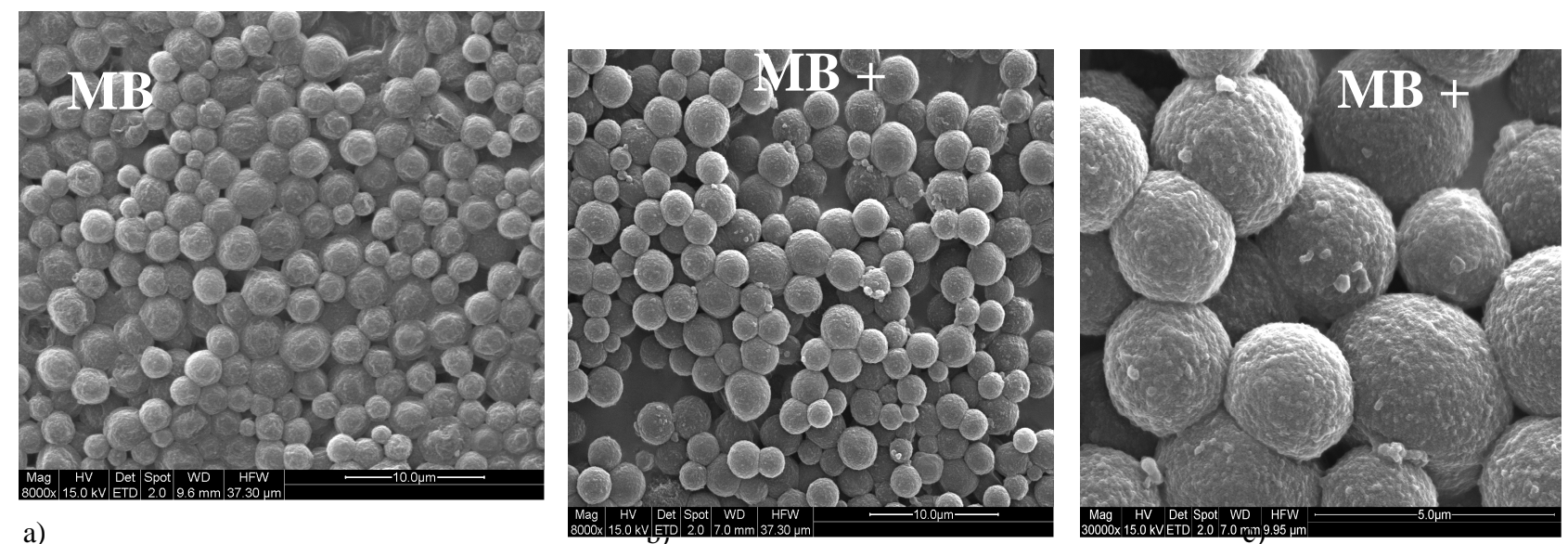

a)

Figure 7 


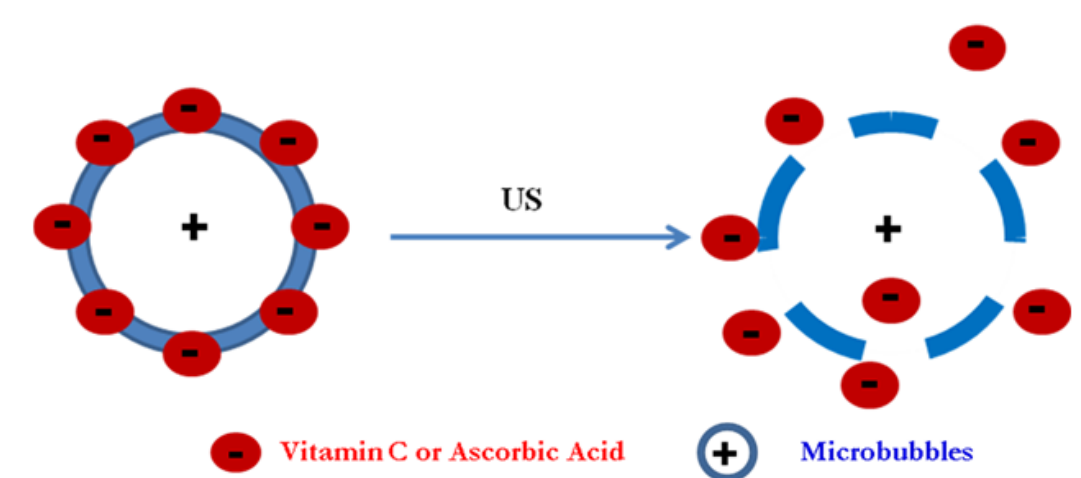

Schematic of the interaction between LSMB (positively charged) and AA (negatively charged).

Ultrasound (US) assisted breaking of the LSMB's shell causes the release of drug located on the surface of the LSMB 


\section{University Library}

\section{- M M I N E R VA A gateway to Melbourne's research publications}

Minerva Access is the Institutional Repository of The University of Melbourne

Author/s:

Cavalieri, F;Micheli, L;Zhou, M;Tortora, M;Palleschi, G;Ashokkumar, M

Title:

Electrochemical investigation of the interaction between lysozyme-shelled microbubbles and vitamin $\mathrm{C}$

Date:

2013-06-01

Citation:

Cavalieri, F., Micheli, L., Zhou, M., Tortora, M., Palleschi, G. \& Ashokkumar, M. (2013). Electrochemical investigation of the interaction between lysozyme-shelled microbubbles and vitamin C. ANALYTICAL AND BIOANALYTICAL CHEMISTRY, 405 (16), pp.5531-5538. https://doi.org/10.1007/s00216-013-6895-0.

Persistent Link:

http://hdl.handle.net/11343/283100 